\title{
Glycoprotein-ELISA Unit Per Milliliter
}

National Cancer Institute

\section{Source}

National Cancer Institute. Glycoprotein-ELISA Unit Per Milliliter. NCI Thesaurus. Code C130190.

A unit for measuring potency of immunologically active substance in a product determined as reactivity in a glycoprotein enzyme-linked immunosorbent assay for particular antigen or antibody and expressed per unit volume equal to one milliliter. 